\title{
Genetic Determinants of Urolithiasis
}

\author{
Carla G. Monico, M.D. ${ }^{1}$ and Dawn S. Milliner, M.D. ${ }^{1}$ \\ ${ }^{1}$ Divisions of Nephrology and Hypertension and Pediatric Nephrology, Departments of Internal \\ Medicine and Pediatric and Adolescent Medicine, Mayo Clinic Hyperoxaluria Center, Mayo Clinic, \\ Rochester, MN, USA
}

\begin{abstract}
Urolithiasis affects approximately $10 \%$ of individuals in Western societies by the seventh decade of life. The most common form, idiopathic calcium oxalate urolithiasis, results from the interaction of multiple genes and their interplay with dietary and environmental factors. To date, considerable progress has been made identifying the metabolic risk factors predisposing to this complex trait, among which hypercalciuria predominates. The specific genetic and epigenetic factors have remained less clear, in part due to the candidate gene and linkage methods available until now, which are inherently low in their power of resolution and in assessing modest effects in complex traits. Even so, this approach, together with investigations of rare, Mendelian forms of urolithiasis associated with various metabolic risk factors has afforded insights into biological pathways that appear to underlie the development of stones in the urinary tract.
\end{abstract}

Monogenic diseases account for a greater proportion of stone formers in childhood and adolescence than in adults. Early diagnosis of monogenic forms of urolithiasis is of importance due to associated renal injury and other potentially treatable disease manifestations, but is often delayed due to lack of familiarity with these rare disorders.

Genetic advances in polygenic and monogenic forms of urolithiasis are reviewed.

\section{Introduction}

Familial clustering of idiopathic calcium oxalate urolithiasis was observed as early as the $19^{\text {th }}$ century, suggesting a genetic basis. ${ }^{1,2}$ For decades, family-based linkage and candidate gene studies have formed the crux of our understanding of genetic susceptibility factors, highlighting a role for disturbances in calcium homeostasis. Recently, the first genome-wide association study in idiopathic calcium oxalate urolithiasis was published, identifying a member of the claudin gene family (CLDN14) as a risk locus. ${ }^{3}$ Members of the same gene family (CLDN16 and CLDN19) have been implicated in monogenic forms of hypercalciuria (FHHNC, see below), ${ }^{4,5}$ serving well to illustrate how complex and simple traits with a common phenotype may interface at the genetic level For single gene Mendelian disorders associated with urolithiasis, discovery of the causative genes and recognition of their variation has made molecular diagnostics and pharmacogenomics possible, while at the same time providing a wealth of suitable candidates to study as quantitative trait loci in the more common complex form of the disease. The genetic advances in common (polygenic) and rare (monogenic) forms of urolithiasis are summarized here.

Corresponding author: Dawn S. Milliner, M.D., Mayo Clinic 200, First Street, SW, Rochester, MN 55905, Telephone: 507-266-1045, Fax: 507-266-7891, milliner.dawn@mayo.edu. 


\section{Idiopathic Calcium Oxalate Urolithiasis: Polygenic Form}

Idiopathic calcium oxalate urolithiasis is a common disorder, affecting approximately $10 \%$ of individuals in Western and affluent societies by the seventh decade of life.$^{6-8}$ It is a cause of significant morbidity due to recurrence rates of $50 \%$ at 5 to 10 years and the frequent necessity for surgical intervention. ${ }^{6,9-13}$ Recent studies have also suggested potential associations with diabetes, hypertension, and loss of renal function. ${ }^{14-17}$ Formation of calcium-containing stones, mixed with oxalate or phosphate is characteristic, and in the majority of instances associated with one or more specific metabolic risk factors: hypercalciuria, hyperoxaluria, hypocitraturia, hyperphosphaturia, hyperuricosuria, low urinary volume and/or defects in urinary acidification or crystal inhibition. Of these, hypercalciuria occurs with the highest frequency, detected in up to $60 \%$ of kidney stone formers, typically in the absence of secondary causes, hence use of the term 'idiopathic' ${ }^{18}$ Proposed mechanisms include intestinal calcium hyper-absorption, increased bone turnover, and a proximal renal tubular 'leak' of calcium. Nevertheless, as is true for many other traits, idiopathic calcium oxalate urolithiasis likely arises from a combination of environmental factors, including the dietary intake of salt, protein, calcium, and fluid, in addition to climate, and socioeconomic status, as well as genetic factors. The latter will be emphasized in this review.

\section{Heredity in Idiopathic Hypercalciuria and Calcium Oxalate Urolithiasis}

Family Studies-The familial association of hypercalciuria and calcium oxalate urolithiasis has been corroborated by numerous studies. In 1968, Resnick et al reported a much higher frequency of calcium oxalate urolithiasis (ranging as high as 20\%) in 625 firstdegree relatives of 106 calcium oxalate stone forming patients when compared to relatives of control subjects. ${ }^{19}$ Coe et al reported an increased incidence of both hypercalciuria and urolithiasis (43\%) in first-degree relatives of 9 probands with hypercalciuria and recurrent calcium oxalate urolithiasis. ${ }^{20}$ More recently, Curhan et al reported an adjusted relative risk of incident kidney stone formation of 2.57 in men with a positive family history, in a very large cohort of 37,999 male health professionals. ${ }^{21}$ From these and other studies, the likelihood of kidney stone formers having affected first-degree or more distant family members has been estimated at 15 to $65 \% .^{22-23}$

Twin Studies: Estimates of Heritability-Studies of kidney stone forming twins have demonstrated a higher concordance in monozygotic than dizygotic twins (32\% vs $17 \%$, respectively, in one study), with estimates of heritability $\left(\mathrm{h}^{2}\right)$ of 52 to $56 \% .^{24-26}$

Linkage and Candidate Gene Studies-Because the majority of kidney stones are calcium-containing ${ }^{27}$ and because hypercalciuria is the most commonly identified metabolic risk factor, the search for susceptibility loci in idiopathic calcium oxalate urolithiasis has logically focused on genes involved in calcium metabolism. Selective breeding of SpragueDawley rats with the highest levels of urinary calcium for more than 30 generations has yielded animals with a phenotype resembling abnormalities of calcium handling observed in subsets of human patients with idiopathic hypercalciuria. ${ }^{28}$ Namely, intestinal calcium hyper-absorption, increased bone resorption and impaired renal tubular calcium reabsorption. ${ }^{29}$ Detailed studies in these rats have demonstrated elevated levels of the vitamin D receptor (VDR) protein in intestine, bone and kidney, as has also been reported in peripheral blood monocytes of some patients with idiopathic hypercalciuria. ${ }^{30}$ VDR upregulation was recently shown to be mediated by Snail, a gene coding for a zinc finger transcription factor, in the same genetic hypercalciuric rat model. ${ }^{31}$ Homologues of the quantitative trait loci associated with hypercalciuria in these animals have served as candidate genes in human idiopathic hypercalciuria (see below). The candidate loci in 
idiopathic hypercalciuria and calcium-containing urolithiasis are listed in Table 1. Candidate genes associated with monogenic causes of hypercalciuria are summarized later in this review (see Rare Monogenic Causes of Urolithiasis Associated with Hypercalciuria, below). The Vitamin D Receptor (VDR)

Several linkage studies of human patients with idiopathic hypercalciuria and calciumcontaining urolithiasis have suggested an association with chromosomal locus 12q12-14, which contains the vitamin D receptor gene but results have been inconclusive. In a large cohort of 47 French Canadian pedigrees, Scott et al showed linkage of the calcium oxalate stone forming phenotype to microsatellite markers in this region but not to hypercalciuria. ${ }^{32}$ In contrast, in a study of 150 kidney stone formers from Northern India, restriction fragment polymorphisms of the vitamin D receptor (BsmI and $F o k I$ ) appeared to correlate with higher urine calcium excretion. ${ }^{33}$ In the study of Heilberg et al, ${ }^{34}$ vitamin D receptor BsmI polymorphism genotypes did not correlate with dietary calcium intake, urinary calcium excretion nor bone mineral density.

The Calcium Sensing Receptor (CaSR)-Studies from Italy have suggested a link between a rare functional single nucleotide polymorphism (R990G) of the CaSR gene (chromosome 3q13.3-21.1), which causes a gain of function of the receptor, and hypercalciuria in 124 women recruited from an outpatient osteoporosis clinic. ${ }^{35}$ But nonparametric linkage and quantitative trait analyses in 64 French Canadian sibships of calcium oxalate and phosphate kidney stone formers with varying degrees of calciuria did not reveal an association with microsatellite markers in the region of the CaSR gene. ${ }^{36}$

Soluble Adenylyl Cyclase (sAC)—Linkage to chromosome 1q23.3-q24, a region containing a putative gene homologous to the rat gene coding for $\mathrm{SAC}$, was demonstrated by Pak et al in 3 kindreds with absorptive hypercalciuria. ${ }^{37}$ Four sequence variants (coding and non-coding) in this hypothetical gene appeared to increase the risk of absorptive hypercalciuria and low bone mineral density. ${ }^{38}$

\section{Epithelial calcium channel (ECaC1) and TRPV5 (Transient Receptor Potential}

Vanilloid Member 5)—Over a decade ago, a novel epithelial channel with a capacity for calcium transport and expression in the distal nephron and proximal small intestine was identified, referred to as the epithelial calcium channel (ECaC). ${ }^{39}$ In the kidney, it was shown to localize to the apical membrane of distal renal cells, along with vitamin D3dependent calbindin- $\mathrm{D}_{28 \mathrm{~K}}$, and to possess highly selective calcium transport properties, pointing to a role as a transcellular calcium 'gate-keeper'. Molecular screening of $\mathrm{ECaC} 1$ in 9 pedigrees with idiopathic hypercalciuria did not reveal any pathogenic sequence variants. ${ }^{40}$ It has since been recognized, however, that this epithelial calcium channel is the apical transient receptor potential vanilloid 5 (TRPV5), acting in close concert with Klotho to modulate calcium reabsorption in the distal renal tubule, a function regulated by vitamin D, parathyroid hormone, and potentially other molecules (e.g. WNK4). ${ }^{41}$ TRPV5 (-/-) mice show significant disturbances in calcium homeostasis similar to human patients with idiopathic hypercalciuria, ${ }^{42}$ including marked hypercalciuria, enhanced dietary calcium absorption, elevated vitamin D levels, and disturbances in bone (reduced trabecular and cortical mass), suggesting a key regulatory role for TRPV5. The human gene coding for TRPV5 is located on chromosome 7q35. ${ }^{43}$ Molecular screening of TRPV5 in 20 patients with renal hypercalciuria revealed 8 single nucleotide base changes but functional characterization of these variants failed to show differences from wild-type TRPV5. ${ }^{44}$

\section{Urinary Macromolecules and Inhibitors of Calcium Oxalate Crystallization-}

Several macromolecules, including Tamm-Horsfall glycoprotein, osteopontin, bikunin, and nephrocalcin, have been detected in calcium oxalate kidney stones. Previous attempts to 
assign a pathogenic role for these macromolecules, by measuring their urinary excretion patterns in stone formers vs controls, and assessing their in vitro effect on calcium oxalate crystal formation or adhesion to renal tubular epithelial cells, have yielded contradictory results.

More recently, the role of single-nucleotide polymorphisms in the genes coding for these substances and the risk of idiopathic calcium oxalate stone formation has been examined. A strong association of several SNPs in the osteopontin gene (T-593A, C6982T, rs1126616, -156delG) with urinary stone formation in Turkish, Japanese and Taiwanese populations has been demonstrated. ${ }^{45-47}$

Similarly, a polymorphism (I550V) in the gene coding for the Na+/dicarboxylate cotransporter (hNaDC-1), a major regulator of urinary citrate excretion has been shown to be associated the risk of recurrent calcium-containing stones. ${ }^{48}$ Urinary citrate is a potent inhibitor of calcium oxalate crystal formation in human urine. Patients homozygous for this variant showed a significantly lower urinary citrate.

\section{Genome Wide Association Study in Idiopathic Calcium Oxalate Urolithiasis}

The family-based linkage and candidate gene approach to identifying genetic variants that confer heritability is inherently limited by sample sizes, numbers of sequence variants assayed, and incomplete knowledge about the disease process in question. The recent availability of single nucleotide polymorphism (SNP) 'chips' that can assay up to a million common human sequence variants in several thousand individuals has surpassed these limitations. In 2009 Thorleifsson et $\mathrm{al}^{3}$ published the first genome-wide association study in urolithiasis research, reporting an association of two common synonymous CLDN14 gene variants (R81R and T229T) with the risk of developing kidney stones and of having reduced bone mineral density in a large Icelandic and Dutch population set. Notably, these risk variants also appeared to associate with biochemical parameters pertinent to calcium metabolism, including urinary calcium, serum bicarbonate and parathyroid hormone level. CLDN14 is a member of the claudin gene family which codes for membrane proteins that regulate paracellular ion transport, with expression in cochlear sensory epithelium. Until now, variants in $C L D N 14$ had only been described in patients with nonsyndromic autosomal recessive deafness. ${ }^{3,49}$

\section{Rare (Monogenic) Forms of Urolithiasis}

Recent insights into the genetic basis and pathophysiology of monogenic causes of urolithiasis have underscored the role of transporter, channel and receptor proteins in the renal tubule (Figure 1) and in other non-renal epithelia, in addition to that of enzymes. Though these Mendelian traits account for only $2 \%$ and $10 \%$ of adult and pediatric kidney stone formers, respectively, ${ }^{50-51}$ they are characterized by more severe stone-forming phenotypes than the common polygenic form, and by progressive renal impairment. Dent's disease, primary hyperoxaluria, adenine phosphoribosyltransferase (APRT) deficiency, hypoxanthine-guanine phosphoribosyl-transferase (HPRT) deficiency and familial hypomagnesemia with hypercalciuria and nephrocalcinosis (FHHNC) in particular, are associated with renal failure. The formation of crystals within renal tubules in these conditions results in an injurious inflammatory response that leads to interstitial fibrosis and development of end-stage renal disease (ESRD). The major genetic defects, classified according to their specific stone-forming metabolic risk factor are summarized in Tables 2 and 3 . 


\section{Early Diagnosis of Monogenic Causes of Urolithiasis: The Key to Prevention}

Clinical recognition of the hereditary forms of urolithiasis can be challenging, due to their rarity, wide spectrum of disease expression over the course of a lifetime, from childhood to adulthood, and common signs and symptoms among the different disorders, including overlap with idiopathic calcium oxalate urolithiasis. Delays in diagnosis are common, with identification of some patients only after the onset of renal failure or when there is disease recurrence in the transplanted kidney after transplantation. In a United States survey of 102 primary hyperoxaluria patients published in 2003, Hoppe and Langman reported a delay in diagnosis of several years in $42 \%$, including $30 \%$ in whom the diagnosis was not established until after ESRD. ${ }^{52}$ Delay in diagnosis until after ESRD was observed in $20 \%$ of patients from the International Primary Hyperoxaluria Registry. ${ }^{53}$ Similar under-recognition of the potential for irreversible loss of renal function, even in the absence of urolithiasis, was published recently in 3 adult patients with 2,8-dihydroxyadeninuria. ${ }^{54}$ It is hence of importance that the diagnosis of monogenic forms of urolithiasis is considered in any patient with childhood onset kidney stones, frequent recurrences of urolithiasis in adolescence or adulthood, nephrocalcinosis or otherwise unexplained renal failure at any age and in those with a family history of these disease manifestations.

\section{The Benefits of Molecular Genetic Testing: Earlier Diagnosis and Treatment}

Identification of the causative genes and knowledge of their pathogenic sequence variants in monogenic forms of urolithiasis have contributed greatly to their earlier diagnosis and treatment. The feasibility of molecular genetic testing using DNA extracted from peripheral white blood cells has replaced the necessity for more invasive diagnostic testing in many instances, including measurement of enzymatic activity in liver tissue or in skin fibroblasts, and blood samples can be transported easily to specialized referral diagnostic laboratories. Moreover, it has made family screening and prenatal testing possible. Genotyping has also become a guide to treatment, predicting a response to therapy in some cases (see below). The accuracy provided by genetic testing combined with registries for patients with these rare diseases are transforming knowledge about disease behavior, and providing new opportunities for study of effective treatments.

\section{Hypercalciuria Dent's Disease (OMIM 300009)}

Inactivating mutations of CLCN5 (Xp.11.22) are the cause of Dent's disease, a collection of syndromes characterized by a proximal tubulopathy, low molecular weight proteinuria, hypercalciuria, calcium urolithiasis, nephrocalcinosis, and progressive renal insufficiency, with or without bone disease. ${ }^{55-56}$ End stage renal failure is often observed in affected males by mid adulthood. Prior to discovery of CLCN5 as the causative gene, several previously described syndromes were considered to be separate diseases: X-linked recessive nephrolithiasis (XRN) with renal failure, $\mathrm{X}$-linked recessive hypophosphatemic rickets (XLRH), low molecular weight proteinuria with hypercalciuria and nephrocalcinosis, and Japanese idiopathic low molecular weight proteinuria (JILMWP). Identification of the specific genetic defect has hence provided a unifying diagnosis. Recently, locus heterogeneity has also been described, with detection of OCRL1 mutations in 13 male probands with a phenotype resembling Dent's disease but negative for $C L C N 5$ mutations. ${ }^{57}$ $C L C N 5$ and $O C R L 1$ code for distinctly different proteins with different expression patterns and functions. $C L C N 5$ codes for a voltage-gated chloride/proton exchanger expressed in the cortical proximal tubule, medullary thick ascending limb of Henle's loop and a-intercalated cells whereas $O C R L 1$ codes for phosphatidylinositol 4,5-biphosphate $\left(\mathrm{PIP}_{2}\right)$ 5-phosphatase, a key regulator of protein trafficking at the plasma membrane, with far more ubiquitous expression. ${ }^{58}$ 
The mechanism by which mutations in these genes cause hypercalciuria and its attendant stone-forming manifestations in Dent's disease remains unclear--though disruption of endosomal membrane trafficking may be a common pathogenic feature. OCRL1 mutations are also the cause of Lowe syndrome, which is characterized by congenital cataracts, mental retardation and defective proximal renal tubular reabsorption, sometimes associated with hypercalciuria and nephrocalcinosis. ${ }^{59}$ So it is not readily understood how they can also result in an isolated form of proximal renal tubular wasting as seen in Dent's patients. At present CLCN5 mutations account for the majority of Dent's families, ${ }^{57,60}$ with description of $>80$ pathogenic variants spread throughout the coding region to date. Correlations between genotype and phenotype are lacking thus far. ${ }^{61-62}$ Molecular screening of CLCN5 in a limited subset of 32 patients with idiopathic hypercalciuria did not reveal any CLCN5 sequence variants, thus failing to show an association with this common condition. ${ }^{63}$

\section{Familial Hypomagnesemia with Hypercalciuria and Nephrocalcinosis (FHHNC)(OMIM 248250 \& 248190)}

Members of the claudin gene family play a prominent role in the paracellular transport of solutes by virtue of their expression in tight junctions of epithelia, where they function as charge selective channels. ${ }^{64}$ Loss-of-function mutations in CLDN16 (also referred to as paracellin 1, PCLN-1) (3q27) give rise to the syndrome of familial hypomagnesemia with hypercalciuria and nephrocalcinosis (FHHNC), a rare autosomal recessive tubular disorder characterized by magnesium and calcium wasting, polyuria, nephrolithiasis, nephrocalcinosis and progressive renal failure, typically of early onset (OMIM 248250). ${ }^{4-5,65} \mathrm{~A}$ similar syndrome, which is characterized by ocular abnormalities in addition to renal tubular manifestations (OMIM 248190), is caused by mutations in CLDN19 (1p34.2), and so far recognized in families of Swiss, Spanish and Turkish descent. ${ }^{5}$ In the kidney, claudin 16 and claudin 19 share parallel expression in the thick ascending limb of Henle's loop and distal convoluted tubule,, which is essential for paracellular reabsorption of calcium and magnesium. Interestingly, Hou et al recently showed that CLDN16 and CLDN19 form a complex in the thick ascending limb of Henle's loop, required for formation of the cation-selective paracellular channel in tight junctions of this nephron segment. ${ }^{66}$

Over 25 CLDN16 mutations have now been catalogued, including missense, nonsense, frameshift, and splice site changes, with evidence that complete loss-of-function variants give rise to earlier symptom onset and more rapid decline in renal function. ${ }^{67}$ Interestingly, a CLDN16 missense variant (T233R) has also been reported in 2 of 11 families screened with isolated hypercalciuria. ${ }^{68}$

\section{Distal Renal Tubular Acidoses}

A number of monogenic clinical conditions are associated with impaired distal renal tubular function resulting in reduced acidification capacity, alkaline urine, hypocitraturia and hypercalciuria. All of these factors predispose to precipitation of calcium phosphate and/or oxalate in renal parenchyma or in renal tubules, and hence urolithiasis and nephrocalcinosis. Functional alterations of the bicarbonate/chloride exchanger 1 (AE1), due to SLC4A1 mutations, are the cause of an autosomal dominant form seen in some families, ${ }^{69-70}$ whereas mutations in genes coding for hydrogen ATPases, ATP6VOA4 and ATP6V1B1, give rise to autosomal recessive transmission. ${ }^{71-74}$

\section{Hereditary Hypophosphatemic Rickets with Hypercalciuria (HHRH, OMIM 241530)}

In 1985, Tieder et al first reported rickets, renal phosphate wasting, hypophosphatemia, upregulation of 1,25-dihydroxyvitamin $\mathrm{D}$, and hypercalciuria in a large consanguineous Bedouin kindred. The syndrome, inherited as an autosomal recessive trait, was coined 
HHRH. Bergwitz et al and Lorenz-Depiereux et al both subsequently identified loss of function mutations in SLC $34 A 3$, the gene coding for the renal sodium phosphate cotransporter (NaPi-IIc), to be the cause. ${ }^{75-76}$ While not recognized as part of the phenotype of the original kindred, subsequent reports have confirmed nephrolithiasis in homozygous affected individuals ${ }^{75,77-78}$ and heterozygous carriers with variable phenotype. ${ }^{79}$

\section{Purine and Pyrimidine Abnormalities}

2, 8-Dihydroxyadeninuria (APRT deficiency)—Deficiency of adenine phosphoribosyltransferase (APRT), a key enzyme in human purine metabolism, causes accumulation of adenine. Oxidation of excess adenine by xanthine dehydrogenase (XDH) then gives rise to 2,8-dihydroxyadeninuria (2,8-DHA), a highly insoluble compound in human urine. Formation of 2,8-DHA crystals causes kidney stones and is injurious to renal parenchyma (Figure 2). Patients often present with kidney stones, but may also present with renal failure in the absence of stones or nephrocalcinosis. Due to radiolucent appearance of DHA stones they can be confused with uric acid on imaging studies. Two types (I and II) are recognized, based on genotype and degree of residual APRT activity. Both inherited as autosomal recessive traits. ${ }^{80}$ Diagnosis relies on analysis of stone material by infrared spectroscopy or detection of 2,8-DHA crystals in the urine, which have a characteristic appearance on microscopy Figure 3), but is confirmed by measurement of APRT activity in erythrocyte lysates and/or by molecular genetic testing. Disease incidence in Iceland is high. A founder effect is suspected, based on reports of two common mutations in Iceland and Caucasian populations from Great Britain. ${ }^{81}$ The prevalence of APRT deficiency in the general population is unknown. However, estimates of homozygosity of 1 in 250,000 to 300,000 based on Caucasian and Japanese allelic frequencies, and 1:250 based on measurement of APRT activity in erythrocyte lysates from an Australian population suggest that it may be more frequent than clinically recognized. ${ }^{82-83}$ Treatment with allopurinol inhibits 2,8-DHA production, and is effective in reducing stone formation as well as ameliorating renal damage. ${ }^{84}$

HPRT Deficiency (HPRT, EC 2.4.2.8; MIM308000)—The vital physiologic role of hypoxanthine-guanine phosphoribosyl-transferase (HPRT) activity in human purine metabolism is emphasized by its absence, which results in Lesch-Nyhan syndrome (MIM300322), characterized by hyperuricemia, hyperuricosuria, early onset uric acid urolithiasis (most commonly in the first year of life) and neurologic complications (mental retardation and self-mutilation). In cases of partial HPRT enzyme deficiency, referred to as Kelley-Seegmiller syndrome, less severe phenotypic manifestations are observed (i.e hyperuricemia, gout), correlated in part to residual HPRT enzymatic activity. Both syndromes result from private or de novo mutations in the X-linked HPRT1 gene (Xq26q27.2), with >300 mutations described so far. ${ }^{85-87}$ The diagnosis is confirmed by determination of HPRT activity in erythrocyte lysates, skin fibroblasts or by molecular genetic analysis. Prenatal testing is available using amniocytes or chorionic villus cells for HPRT enzymatic assay or genetic testing. Notably, a potential for renal failure exists, which can be of pediatric onset. ${ }^{88}$ Treatment with allopurinol is effective in reducing the hyperuricemia and hyperuricosuria but in the case of complete HPRT deficiency (i.e. LeschNyhan syndrome), xanthine urolithiasis may develop during allopurinol treatment, due to urinary elevations of xanthine and hypoxanthine, requiring adjustments in dosing. ${ }^{89}$

Xanthinuria/Hypoxanthinuria (XDH deficiency)(OMIM 278300)—Deficiency of xanthine dehydrogenase (XDH) due to mutations in the $X D H$ gene (2p22) also results in impaired purine degradation, in this instance characterized by urinary elevations of xanthine and hypoxanthine but with hypouricemia and hypouricosuria. The disease is more common 
in Mediterranean and Middle Eastern regions of the world and is inherited as an autosomal recessive trait. ${ }^{90}$ The development of xanthine stones in affected patients is variable.

\section{Hyperoxaluria}

The primary hyperoxalurias are rare inborn errors of glyoxylate metabolism resulting in marked hepatic overproduction and urinary excretion of oxalate, typically in excess of 1.0 $\mathrm{mmol} / 1.73 \mathrm{~m}^{2} / 24 \mathrm{hrs}$ (normal $<0.46 \mathrm{mmol} / 1.73 \mathrm{~m}^{2} / 24 \mathrm{hrs}$ ). The prevalence in central Europe, estimated from a French epidemiologic survey, is 1 to 3 per million population. ${ }^{91}$ Prevalence in the U.S. is unknown. The very high urine oxalate concentrations favor calcium oxalate crystallization and aggregation, giving rise to calcium oxalate kidney stone formation and nephrocalcinosis. Most patients develop symptoms due to stone disease, though a minority initially present with end stage kidney failure. Signs and symptoms most commonly develop in early childhood, though the age at presentation varies widely, from infancy to adulthood. An inflammatory response, mediated by the presence of calcium oxalate crystals in renal tubules and interstitium (Figure 4), causes progressive renal damage over time. End stage renal failure occurred at a median age of 33 years in patients of the International Primary Hyperoxaluria Registry, but may be seen in type 1 primary hyperoxaluria patients as early as infancy or as late as the $6^{\text {th }}$ decade of life. ${ }^{53}$ Among the three types of PH thus far described, type 1 accounts for the majority of patients and is the most clinically severe.. An evidence-based, systematic approach can guide the diagnosis of the primary hyperoxalurias. ${ }^{92}$

Primary Hyperoxaluria Type 1 (PH1) (OMIM259900)—PH1 is caused by deficiency of the liver-specific, peroxisomal enzyme alanine:glyoxylate aminotransferase (AGT), which requires vitamin B6 (pyridoxal phosphate) as a co-factor. ${ }^{93}$ AGT catalyzes the conversion of glyoxylate to glycine but in its absence, glyoxylate is oxidized to oxalate and reduced to glycolate instead. Persistent and marked hyperoxaluria is evident from infancy on, though the degree of hyperglycolic aciduria is variable. Over 100 mutations in the gene coding for AGT (AGXT, 2q37.2) have now been described. Molecular diagnosis is possible in most patients. ${ }^{94-97}$ Availability of genotyping has also facilitated specific treatment. Approximately one-third of patients experience a significant reduction in urine oxalate excretion while receiving pharmacologic doses of vitamin $\mathrm{B} 6$, a response that has been associated with the most common mutation (c.508 G>A, G170R), which causes a unique peroxisome-to-mitochondria trafficking defect, ${ }^{98}$ as well as a few other mutations. ${ }^{99}$ High fluid intake and inhibitors of calcium oxalate crystallization (citrate or neutral phosphate) are used to ameliorate stone formation and renal injury. At present, orthotopic liver transplantation remains the sole definitive means of correcting the metabolic defect. Simultaneous kidney transplantation is typically performed to manage renal failure.

Primary Hyperoxaluria Type 2 (PH2) (OMIM260000)—Deficiency of cytosolic hepatic glyoxylate/hydroxypyruvate reductase (GRHPR) activity causes PH2. ${ }^{100}$ GRHPR has dual enzymatic activities, catalyzing the reductions of glyoxylate to glycolate and of hydroxypyruvate to D-glycerate in human liver. While signs and symptoms and elevations in urinary oxalate may parallel those seen in $\mathrm{PH} 1,{ }^{101}$ there are a few notable differences between the two disorders. In PH2, L-glyceric aciduria is often present with the hyperoxaluria. ${ }^{102}$ Pyridoxine is not effective in $\mathrm{PH} 2$...In contrast to AGT, whose activity is liver-specific, tissue expression of GRHPR is not limited to liver Orthotopic liver transplantation is not currently recommended for treatment of PH2. Rather, kidney-only transplantation is used to address renal failure. To date, fewer than 20 GRHPR mutations have been described, with a minor deletion (c.103delG) accounting for the majority of PH2 alleles (allelic frequency of $\sim 37 \%$ in Caucasian PH2 samples). ${ }^{94,} 103-104$ 
Primary Hyperoxaluria Type 3 (PH3) —A third type of primary hyperoxaluria (PH3) has been recognized clinically for some time in patients with early onset of nephrolithiasis and marked hyperoxaluria indistinguishable from $\mathrm{PH} 1$ and $\mathrm{PH} 2$ but whose hepatic AGT and GRHPR activities are normal. ${ }^{105}$ Recently, mutations in the HOGAl gene have been determined to be responsible. ${ }^{106}$ The disease appears to be autosomal recessive, though its inheritance is not yet fully understood. ${ }^{107}$ The hyperoxaluria is believed to result from deficiency of the hepatic mitochondrial enzyme 4-hydroxy-2-oxoglutarate aldolase. Early experience suggests that the prevalence of PH3 is similar to that of PH2. ${ }^{107}$

\section{Other Inborn Errors}

Cystinuria (OMIM 220100)—Cystinuria is an autosomal recessive trait caused by defective proximal renal and gastrointestinal reabsorption of cystine and the dibasic amino acids due to mutations in the genes (SLC3Al and SLC7A9) coding for these amino acid transporters. ${ }^{108-111}$ The reported prevalence of cystinuria varies widely, depending on the population tested, ranging from $1 / 2500$ in Libyan Jews to $1 / 100,000$ in Sweden. ${ }^{112-113}$ Identification of the causative loci has facilitated a molecular-based classification system (types A and B), replacing the prior characterization scheme which relied largely on urinary amino acid excretion patterns (Types I and Non-I) in obligate heterozygotes. Type A disease is due to two mutations in SLC3A1 (2p16) and Type B disease to two mutations in SLC7A9 (19q13.11) though do not explain all cases. ${ }^{114}$ To date, more than 200 pathogenic single nucleotide variants (coding and non-coding) and large gene rearrangements have been described. ${ }^{114}$ The markedly elevated levels of urinary cystine, a highly insoluble (solubility $\sim 300 \mathrm{mg} / \mathrm{L}$ ) compound, predispose to recurrent stone formation. Hexagonal cystine crystals in the urine are pathognomonic (Figure 5). Frequent stones are the most common manifestation, though some patients also experience gradual loss in renal function. The mainstay of treatment consists of urinary dilution, alkalinization and reduction of cystine to its more soluble metabolite, cysteine using agents such as alpha-mercaptoprotionylglycine and D-penicillamine.

\section{The Future: Patient Registries for Rare Disorders}

Due to the rarity and phenotypic heterogeneity of the monogenic forms of nephrolithiasis, most physicians will have limited familiarity with disease expression, appropriate diagnostic steps, and treatment. Progress in understanding the natural history of these disorders has been slow due to small numbers of patients who are widely scattered geographically. The recent creation of rare diseases patient registries holds promise to overcome these challenges, facilitating recruitment of sufficient numbers of affected patients for study and participation in clinical trials (www.rarediseasesnetwork.org). Early experience of the Rare Kidney Stone Consortium, which houses patient registries for primary hyperoxaluria, Dent's disease, APRT deficiency and cystinuria, confirms the feasibility of this approach.

\section{Conclusions}

Our knowledge of the influence of genes in polygenic and monogenic forms of urolithiasis has evolved greatly in the past century, eliciting an appreciation for the participatory role of a variety of proteins, including enzymes, transporters, channels and receptor proteins in the kidney and other organ systems. For the common polygenic form of urolithiasis, family linkage and candidate gene studies have highlighted aberrations of calcium metabolism. In the future, higher-powered genome-wide association and replication studies will undoubtedly identify additional risk loci, opening an avenue for identification of new therapeutic targets and approaches to treatment. For the rare monogenic disorders, advances in molecular genetics and pharmacogenomics have revolutionized diagnosis and treatment, while at the same time providing important insights into mechanisms that may contribute to 
the more common polygenic forms of urolithiasis. Development of rare disease patient registries will serve to improve patient outcomes, by raising awareness through advocacy, research and consolidation of clinical experience.

\section{References}

1. Clubbe WH. Hereditariness of stone. Lancet. 1872; 1:204.

2. Clubbe WH. Family disposition to urinary concretions. Lancet. 1874; 1:823.

3. Thorleifsson G, et al. Sequence variants in the CLDN14 gene associate with kidney stones and bone mineral density. Nature Genet. 2009; 41:926-930. [PubMed: 19561606]

4. Weber S, et al. Novel paracellin-1 mutations in 25 families with familial hypomagnesemia with hypercalciuria and nephrocalcinosis. J Am Soc Nephrol. 2001; 12:1872-1881. [PubMed: 11518780]

5. Konrad M, et al. Mutations in the tight-junction gene claudin 19 (CLDN19) are associated with renal magnesium wasting, renal failure, and severe ocular involvement. Am J Human Genet. 2006; 79:949-957. [PubMed: 17033971]

6. Johnson CM, Wilson DM, O'Fallon WM, Malek RS, Kurland LT. Renal stone epidemiology: a 25year study in Rochester, Minnesota. Kidney Int. 1979; 16:624-631. [PubMed: 548606]

7. Soucie JM, Thun MJ, Coates RJ, McClellan W, Austin H. Demographic and geographic variability of kidney stones in the United States. Kidney Int. 1994; 46:893-899. [PubMed: 7996811]

8. Hiatt RA, Friedman GD. The frequency of kidney and urinary tract diseases in a defined population. Kidney Int. 1982; 22:63-68. [PubMed: 6181284]

9. Ljunghall S. Renal stone disease. Studies of epidemiology and calcium metabolism. Scand J Urol Nephrol. 1977; 41:1-96. [PubMed: 615339]

10. Sutherland JW, Parks JH, Coe FL. Recurrence after a single renal stone in a community practice. Miner Electrolyte Metab. 1985; 11:267-269. [PubMed: 4033604]

11. Marshall V, White RH, De Saintonge MC, Tresidder GC, Blandy JP. The natural history of renal and ureteric calculi. Br J Urol. 1975; 47:117-124. [PubMed: 1097021]

12. Stamatelou KK, Francis ME, Jones CA, Curhan GC. Time trends in reported prevalence of kidney stones in the United States: 1976-1994. Kidney Int. 2003; 63:1817-1823. [PubMed: 12675858]

13. Strohmaier WL. Course of calcium stone disease without treatment. What can we expect? Eur Urol. 2000; 37:339-344. [PubMed: 10720863]

14. Gambaro G, Favaro S, D'Angelo A. Risk for renal failure in nephrolithiasis. Am J Kidney Dis. 2001; 37:233-243. [PubMed: 11157364]

15. Worcester E, Park JH, Josephson MA, Thisted RA, Coe FL. Causes and consequences of kidney loss in patients with nephrolithiasis. Kidney Int. 2003; 64:2204-2213. [PubMed: 14633144]

16. Worcester E, Parks JH, Evan AP, Coe FL. Renal function in patients with nephrolithiasis. J Urol. 2006; 176:600-603. [PubMed: 16813897]

17. Saucier NA, et al. Risk factors for CKD in persons with kidney stones: a case-control study in Olmsted County, Minnesota. Am J Kidney Dis. 2010; 55:61-68. [PubMed: 19853335]

18. Henneman PH, Benedict PH, Forbes AP, Dudley HR. Idiopathic hypercalciuria. New Engl J Med. 1958; 259:802-807. [PubMed: 13590453]

19. Resnick M, Pridgen DB, Goodman HO. Genetic predisposition to formation of calcium oxalate renal calculi. New Engl J Med. 1968; 278:1313-1318. [PubMed: 5648597]

20. Coe FL, Parks JH, Moore ES. Familial idiopathic hypercalciuria. New Engl J Med. 1979; 300:337340. [PubMed: 759893]

21. Curhan GC, Willett WC, Rimm EB, Stampfer MJ. Family history and risk of kidney stones. J Am Soc Nephrol. 1997; 8:1568-1573. [PubMed: 9335385]

22. McGeown MG. Heredity in renal stone disease. Clin Sci. 1960; 19:465-471. [PubMed: 13773937]

23. Stechman MJ, Loh NY, Thakker RV. Genetics of hypercalciuric nephrolithiasis: renal stone disease. Ann N Y Acad Sci. 2007; 1116:461-484. [PubMed: 17872384]

24. Goldfarb DS, Fischer ME, Keich Y, Goldberg J. A twin study of genetic and dietary influences on nephrolithiasis: a report from the Vietnam era twin (VET) registry. Kidney Int. 2005; 67:10531061. [PubMed: 15698445] 
25. Hunter DJ, et al. Genetic contribution to renal function and electrolyte balance: a twin study. Clin Sci. 2002; 103:259-265. [PubMed: 12193151]

26. Monga M, Macias B, Groppo E, Hargens A. Genetic heritability of urinary stone risk in identical twins. J Urol. 2006; 175:2125-2128. [PubMed: 16697817]

27. Herring LC. Observations on the analysis of ten thousand urinary calculi. J Urol. 1962; 88:545562. [PubMed: 13954078]

28. Hoopes RR, et al. Quantitative trait loci for hypercalciuria in a rat model of kidney stone disease. J Am Soc Nephrol. 2003; 14:1844-1850. [PubMed: 12819244]

29. Bushinsky DA. Genetic hypercalciuric stone-forming rats. Curr Opin Nephrol Hypertens. 1999; 8:479-488. [PubMed: 10491744]

30. Favus MJ, Karnauskas AJ, Parks JH, Coe FL. Peripheral blood monocyte vitamin D receptor levels are elevated in patients with idiopathic hypercalciuria. J Clin Endo Metab. 2004; 89:4937-4943.

31. Bai S, Wang H, Shen J, Zhou R, Bushinsky DA, Favus MJ. Elevated vitamin D receptor levels in genetic hypercalciuric stone-forming rats are associated with down-regulation of snail. J Bone Miner Res. Epub, November 24, 2009.

32. Scott P, et al. Suggestive evidence for a susceptibility gene near the vitamin D receptor locus in idiopathic calcium stone formation. J Am Soc Nephrol. 1999; 10:1007-1013. [PubMed: 10232686]

33. Relan V, Khullar M, Singh SK, Sharma SK. Association of vitamin D receptor genotypes with calcium excretion in nephrolithiatic subjects in northern India. Urol Res. 2004; 32:236-240. [PubMed: 15205858]

34. Heilberg IP, Teixeira SH, Martini LA, Boim MA. Vitamin D receptor gene polymorphism and bone mineral density in hypercalciuric calcium-stone-forming patients. Nephron. 2002; 90:51-57. [PubMed: 11744805]

35. Vezzoli G, et al. R990G polymorphism of calcium-sensing receptor does produce a gain-offunction and predispose to primary hypercalciuria. Kidney Int. 2007; 71:1155-1162. [PubMed: 17332735]

36. Petrucci M, et al. Evaluation of the calcium-sensing receptor gene in idiopathic hypercalciuria and calcium nephrolithiasis. Kidney Int. 2000; 58:38-42. [PubMed: 10886547]

37. Reed BY, Heller HJ, Gitomer WL, Pak CYC. Mapping a gene defect in absorptive hypercalciuria to chromosome 1q23.3-q24. J Clin Endo Metab. 1999; 84:3907-3913.

38. Reed BY, et al. Identification and characterization of a gene with base substitutions associated with the absorptive hypercalciuria phenotype and low spinal bone density. J Clin Endo Metab. 2002; 87:1476-1485.

39. Hoenderop JGJ, et al. Molecular identification of the apical $\mathrm{Ca}^{2+}$ channel 1,25- dihydroxyvitamin D3-responsive epithelia. J Biol Chem. 1999; 274:8375-8378. [PubMed: 10085067]

40. Müller D. Epithelial $\mathrm{Ca}^{2+}$ channel (ECAC1) in autosomal dominant idiopathic hypercalciuria. Nephrol Dial Transplant. 2002; 17:1614-1620. [PubMed: 12198212]

41. Jiang Y, Ferguson WB, Peng JB. WNK4 enhances TRPV5-mediated calcium transport: potential role in hypercalciuria of familial hyperkalemic hypertension caused by gene mutation of WNK4. Am J Physiol Renal Physiol. 2007; 292:F545-F554. [PubMed: 17018846]

42. Hoenderop JGJ, et al. Renal $\mathrm{Ca}^{2+}$ wasting, hyperabsorption, and reduced bone thickness in mice lacking TRPV5. J Clin Invest. 2003; 112:1906-1914. [PubMed: 14679186]

43. Peng JB, Brown EM, Hediger MA. Structural conservation of the genes encoding CaT1, CaT2, and related cation channels. Genomics. 2001; 76:99-109. [PubMed: 11549322]

44. Renkema KY, et al. TRPV5 gene polymorphisms in renal hypercalciuria. Nephrol Dial Transplant. 2009; 24:1919-1924. [PubMed: 19131347]

45. Gao B, et al. Association of osteopontin gene haplotypes with nephrolithiasis. Kidney Int. 2007; 72:592-598. [PubMed: 17519954]

46. Gögebakan B, et al. Association between the T-593A and C6982T polymorphisms of the osteopontin gene and risk of developing nephrolithiasis. Arch Med Res. 2010; 41:442-448. [PubMed: 21044748] 
47. Liu CC, et al. The impact of osteopontin promoter polymorphisms on the risk of calcium urolithiasis. Clin Chim Acta. 2010; 411:739-743. [PubMed: 20144595]

48. Okamoto N, Aruga S, Matsuzaki S, Takahashi S, Matsushita K, Kitamura T. Associations between renal sodium-citrate cotransporter (HnaDC-1) gene polymorphism and urinary citrate excretion in recurrent renal calcium stone formers and normal controls. Int J Urol. 2007; 14:344-349. [PubMed: 17470169]

49. Wilcox ER, et al. Mutations in gene encoding tight junction claudin-14 cause autosomal recessive deafness DFNB29. Cell. 2001; 104:165-172. [PubMed: 11163249]

50. Jungers P, Joly D, Blanchard A, Courbebaisse M, Knebelmann B, Daudon M. Inherited monogenic kidney stone diseases: recent diagnostic and therapeutic advances. Nephrol Ther. 2008; 4:231255. [PubMed: 18499551]

51. Milliner, DS. Requisite in Pediatrics: Nephrology/Urology. Kaplan, BS.; Myers, K., editors. Mosby; St. Louis: 2004. p. 361-374.

52. Hoppe B, Langman CB. A United States survey on diagnosis, treatment, and outcome of primary hyperoxaluria. Pediatr Nephrol. 2003; 18:986-991. [PubMed: 12920626]

53. Lieske JC, et al. International registry for primary hyperoxaluria. Am J Nephrol. 2005; 25:290 296. [PubMed: 15961949]

54. Nasr SH, et al. Crystalline nephropathy due to 2,8-dihydroxyadeninuria: an under-recognized cause of irreversible renal failure. Nephrol Dial Transplant. Epub January 2010.

55. Wrong OM, Norden AG, Feest TG. Dent's disease; a familial proximal renal tubular syndrome with low-molecuar-weight proteinuria, hypercalciuria, and nephrocalcinosis, metabolic bone disease, progressive renal failure and a marked male predominance. QJM. 1994; 87:473-493. [PubMed: 7922301]

56. Lloyd SE, et al. A common molecular basis for three inherited kidney stone diseases. Nature. 1996; 379:445-449. [PubMed: 8559248]

57. Hoopes RR, et al. Dent disease with mutations in OCRL1. Am J Hum Genet. 2005; 76:260-267. [PubMed: 15627218]

58. Lowe M. Structure and function of the lowe syndrome protein OCRL1. Traffic. 2005; 6:711-719. [PubMed: 16101675]

59. Sliman GA, Winters WD, Shaw DW, Avner ED. Hypercalciuria and nephrocalcinosis in the oculocerebrorenal syndrome. J Urol. 1995; 153:1244-1246. [PubMed: 7869519]

60. Utsch B, et al. Novel OCRL1 mutations in patients with the phenotype of dent disease. Am J Kidney Dis. 2006; 48:942-954. [PubMed: 17162149]

61. Tosetto E, et al. Phenotypic and genetic heterogeneity in dent's disease - results of an Italian collaborative study. Nephrol Dial Transplant. 2006; 21:2452-2463. [PubMed: 16822791]

62. Scheinman SJ. X-linked hypercalciuric nephrolithiasis: clinical syndromes and chloride channel mutations. Kidney Int. 1998; 53:3-17. [PubMed: 9452994]

63. Scheinman SJ, et al. Isolated hypercalciuria with mutation in CLCN5: relevance to idiopathic hypercalciuria. Kidney Int. 2000; 57:232-239. [PubMed: 10620204]

64. Colegio OR, Van Itallie CM, McCrea HJ, Rahner C, Anderson JM. Claudins create chargeselective channels in the paracellular pathway between epithelial cells. Am J Physiol Cell Physiol. 2002; 283:142-147.

65. Simon DB, et al. Paracellin-1, a renal tight junction protein required for paracellular $\mathrm{Mg}^{2+}$ resorption. Science. 1999; 285:103-106. [PubMed: 10390358]

66. Hou J, et al. Claudin-16 and claudin-19 interaction is required for their assembly into tight junctions and for renal reabsorption of magnesium. Proc Natl Acad Sci USA. 2009; 106:1535015355. [PubMed: 19706394]

67. Konrad M, et al. CLDN16 genotype predicts renal decline in familial hypomagnesemia with hypercalciuria and nephrocalcinosis. J Am Soc Nephrol. 2008; 19:171-181. [PubMed: 18003771]

68. Müller D, et al. A novel claudin 16 mutation associated with childhood hypercalciuria abolishes binding to ZO-1 and results in lysosomal mistargeting. Am J Hum Genet. 2003; 73:1293-1301. [PubMed: 14628289] 
69. Bruce LJ, Unwin RJ, Wrong O, Tanner MJ. The association between familial distal renal tubular acidosis and mutations in the red cell anion exchanger (band 3, AE1) gene. Biochem Cell Biol. 1998; 76:723-728. [PubMed: 10353704]

70. Cheidde L, Vieira TC, Lima PR, Saad ST, Heilberg IP. A novel mutation in the anion exchanger 1 gene is associated with familial distal renal tubular acidosis and nephrocalcinosis. Pediatrics. 2003; 112:1361-1367. [PubMed: 14654610]

71. Karet FE, et al. Localization of a gene for autosomal recessive distal renal tubular acidosis with normal hearing (rdRTA2) to 7q33-34. Am J Hum Genet. 1999; 65:1656-1665. [PubMed: 10577919]

72. Karet FE, et al. Mutations in the gene encoding B1 subunit of H+-ATPase cause renal tubular acidosis with sensorineural deafness. Nat Genet. 1999; 21:84-90. [PubMed: 9916796]

73. Smith AN, et al. Mutations in ATP6N1B, encoding a new kidney vacuolar proton pump 116-kD subunit, cause recessive distal renal tubular acidosis with preserved hearing.

74. Stover EH, et al. Novel ATP6V1B1 and ATP6V0A4 mutations in autosomal recessive distal renal tubular acidosis with new evidence for hearing loss. J Med Genet. 2002; 39:796-803. [PubMed: 12414817]

75. Bergwitz C, et al. SLC34A3 mutations in patients with hereditary hypophosphatemic rickets with hypercalcliuria predict a key role for the sodium-phosphate cotransporter NaPi-IIc in maintaining phosphate homeostasis. Am J Hum Genet. 2006; 78:179-192. [PubMed: 16358214]

76. Lorenz-Depiereux B, et al. Hereditary hypophosphatemic rickets with hypercalciuria is caused by mutations in the sodium-phosphate cotransporter gene SLC34A3. Am J Hum Genet. 2006; 78:193-201. [PubMed: 16358215]

77. Jaureguiberry G, Carpenter TO, Forman S, Juppner H, Bergwitz C. A novel missense mutation in SLC34A3 that causes hereditary hypophosphatemic rickets with hypercalciuria in humans identifies threonine 137 as an important determinant of sodium-phosphate cotransport in NaPi-IIc. Am J Physiol Renal Physiol. 2008; 295:F371-F379. [PubMed: 18480181]

78. Tencza AL, et al. Hypophsphatemic rickets with hypercalciuria due to mutation in SLC34A3/type IIc sodium-phosphate cotransporter: presentation as hypercalciuria and nephrolithiasis. J Clin Endocrinol Metab. 2009; 94:4433-4438. [PubMed: 19820004]

79. Ichikawa S, Sorenson AH, Imel EA, Friedman NE, Gertner JM, Econs MJ. Intronic deletions in the SLC34A3 gene cause hereditary hypophosphatemic rickets with hypercalciuria. J Clin Endocrinol Metab. 2006; 91:4022-4027. [PubMed: 16849419]

80. Simmons, HA.; Sahota, AS.; Van Acker, KJ. The Metabolic Basis of of Inherited Disease. Scriver, CR.; Beaudet, AL.; Sly, WS.; Valle, D., editors. McGraw-Hill; New York: 1989. p. 1029-1044.

81. Van Edvardsson V, Palsson R, Olafsson I, Hjaltadottir G, Laxdal T. Clinical features and genotype of adenine phosphoribosyltransferase deficiency in Iceland. Am J Kidney Dis. 2001; 38:473-480. [PubMed: 11532677]

82. Di Pietro V, et al. Clinical, biochemical and molecular diagnosis of a compound homozygote for the $254 \mathrm{bp}$ deletion- $8 \mathrm{bp}$ insertion of the APRT gene suffering from severe renal failure. Clin Biochem. 2007; 40:73-80. [PubMed: 17126311]

83. Johnson LA, Gordon RB, Emmerson BT. Adenine phosphoribosyltransferase: a simple spectrophotometric assay and the incidence of mutation in the normal population. Biochem Genet. 1977; 15:265-272. [PubMed: 869896]

84. Bollee G, et al. Adenine phosphoribosyltransferase (APRT) deficiency: phenotype and genotype characterization of a large cohort. J Am Soc Nephrol. (in press).

85. Torres RJ, Prior C, Puig JG. Efficacy and safety of allopurinol in patients with hypoxanthineguanine phosphoribosyltransferase deficiency. Metab Clin Exp. 2007; 56:1179-1186. [PubMed: 17697859]

86. Jinnah HA, De Gregorio L, Harris JC, Nyhan WL, O'Neill JP. The spectrum of inherited mutations causing HPRT deficiency: 75 new cases and a review of 196 previously reported cases. Mutat Res. 2000; 463:309-326. [PubMed: 11018746]

87. Torres RJ, et al. Molecular basis of hypoxanthine-guanine phosphoribosyltransferase deficiency in thirteen Spanish families. Hum Mutat. 2000; 15:383. [PubMed: 10737990] 
88. Ishida Y, et al. Partial hypoxanthine-guanine phosphoribosyltransferase deficiency due to a newly recognized mutation presenting with renal failure in a one-year-old boy. Eur J Pediatr. 2008; 167:957-959. [PubMed: 17891542]

89. Torres RJ, Puig JG. Hypoxanthine-guanine phosphoribosyltransferase (HPRT) deficiency: LeschNyhan syndrome. Orphanet J Rare Dis. 2007; 2:48. [PubMed: 18067674]

90. Arikyants N, Sarkissian A, Hesse A, Eggermann T, Leumann E, Steinmann B. Xanthinuria type 1: a rare cause of urolithiasis. Pediatr Nephrol. 2007; 22:310-314. [PubMed: 17115198]

91. Cochat P, Deloraine A, Rotily M, Olive F, Liponski I, Deries N. Epidemiology of primary hyperoxaluria type 1 . Société de Néphrologie and the Société de Néphrologie Pédiatrique. Nephrol Dial Transplant. 1995; 10:3-7. [PubMed: 8592622]

92. Milliner DS, et al. Diagnostic algorithm for the primary hyperoxalurias. Am J Nephrol. 2005; 25:154-160. [PubMed: 15855742]

93. Danpure CJ, Jennings PR. Peroxisomal alanine:glyoxylate aminotransferase deficiency in primary hyperoxaluria type 1. FEBS Lett. 1986; 26:20-24. [PubMed: 3709805]

94. Rumsby G, Williams E, Coulter-Mackie M. Evaluation of mutation screening as a first line test for the diagnosis of primary hyperoxalurias. Kidney Int. 2004; 66:959-963. [PubMed: 15327387]

95. Williams E, Rumsby G. Selected exonic sequencing of the AGXT gene provides a genetic diagnosis in 50\% of patients with primary hyperoxaluria type 1. Clin Chem. 2007; 53:1216-1221. [PubMed: 17495019]

96. Monico CG, et al. Comprehensive mutation screening in 55 probands with type 1 primary hyperoxaluria shows feasibility of a gene-based diagnosis. J Am Soc Nephrol. 2007; 18:19051914. [PubMed: 17460142]

97. Wiliams EL, et al. Primary hyperoxaluria type 1: update and additional mutation analysis of the AGXT gene. Hum Mutat. 2009; 30:910-917. [PubMed: 19479957]

98. Monico CG, Rossetti S, Olson JB, Milliner DS. Pyridoxine effect in type I primary hyperoxaluria is associated with the most common mutant allele. Kidney Int. 2005; 67:1704-1709. [PubMed: 15840016]

99. Monico CG, Olson JB, Milliner DS. Implications of genotype and enzyme phenotype in pyridoxine response of patients with type I primary hyperoxaluria. Am J Neph. 2005; 25:183-188.

100. Giafi CF, Rumsby G. Kinetic analysis and tissue distribution of human D-glycerate dehydrogenase/glyoxylate reductase and its relevance to the diagnosis of primary hyperoxaluria type 2. Ann Clin Biochem. 1998; 35:688.

101. Milliner DS, Wilson DM, Smith LH. Phenotypic expression of primary hyperoxaluria: comparative features of types I and II. Kidney Int. 2001; 59:31-36. [PubMed: 11135054]

102. Williams HE, Smith LH. L-glyceric aciduria. A new genetic variant of primary hyperoxaluria. N Engl J Med. 1968; 278:233-238. [PubMed: 5635456]

103. Webster KE, Ferree PM, Holmes RP, Cramer SD. Identification of missense, nonsense, and deletion mutations in the GRHPR gene in patients with primary hyperoxaluria type II (PH2). Hum Genet. 2000; 107:176-185. [PubMed: 11030416]

104. Cregeen DP, Williams EL, Hulton S, Rumsby G. Molecular analysis of the glyoxylate reductase (GRHPR) gene and description of mutations underlying primary hyperoxaluria type 2. Hum Mutat. 2003; 22:497. [PubMed: 14635115]

105. Monico CG, Persson M, Ford GC, Rumsby G, Milliner DS. Potential mechanisms of marked hyperoxaluria not due to primary hyperoxaluria I or II. Kidney Int. 2002; 62:392-400. [PubMed: 12110000]

106. Belostotsky R, et al. Mutations in DHDPSL are responsible for primary hyperoxaluria type III. Am J Hum Genet. 2010; 87:392-399. [PubMed: 20797690]

107. Monico CG, et al. Analysis of the primary hyperoxaluria type III gene, HOGA1 (formerly DHDPSL), reveals inactivating mutations and a possible risk factor for idiopathic calcium oxalate urolithiasis. Clin J Am Soc Nephrol. 2011 In press.

108. Calonge MJ, et al. Cystinuria cused by mutations in rBAT, a gene involved in the transport of cystine. Nat Genet. 1994; 6:420-425. [PubMed: 8054986]

109. Purroy J, et al. Genomic structure and organization of the human rBAT gene (SLC3A1). Genomics. 1996; 15:249-252. [PubMed: 8921402] 
110. Chesney RW. Mutational analysis of patients with cystinuria detected by a genetic screening network: powerful tools in understanding the several forms of the disorder. Kidney Int. 1998; 54:279-280. [PubMed: 9648090]

111. Feliubadalo L, et al. Non-type I cystinuria caused by mutations in SLC7A9, encoding a subunit (bo,+AT) of rBAT. Nat Genet. 1999; 23:52-57. [PubMed: 10471498]

112. Bruno M, Marangella M. Cystinuria: recent advances in pathophysiology and genetics. Contrib Nephrol. 1997; 122:173-177. [PubMed: 9399061]

113. Goodyer P, Boutros M, Rozen R. The molecular basis of cystinuria: an update. Exp Nephrol. 2000; 8:123-127. [PubMed: 10810228]

114. Bisceglia L, et al. Large rearrangements detected by MLPA, point mutations, and survey of the frequency of mutations within the SLC3A1 and SLC7A9 genes in a cohort of 172 cystinuric Italian patients. Molec Genet Metab. 2010; 99:42-52. [PubMed: 19782624] 


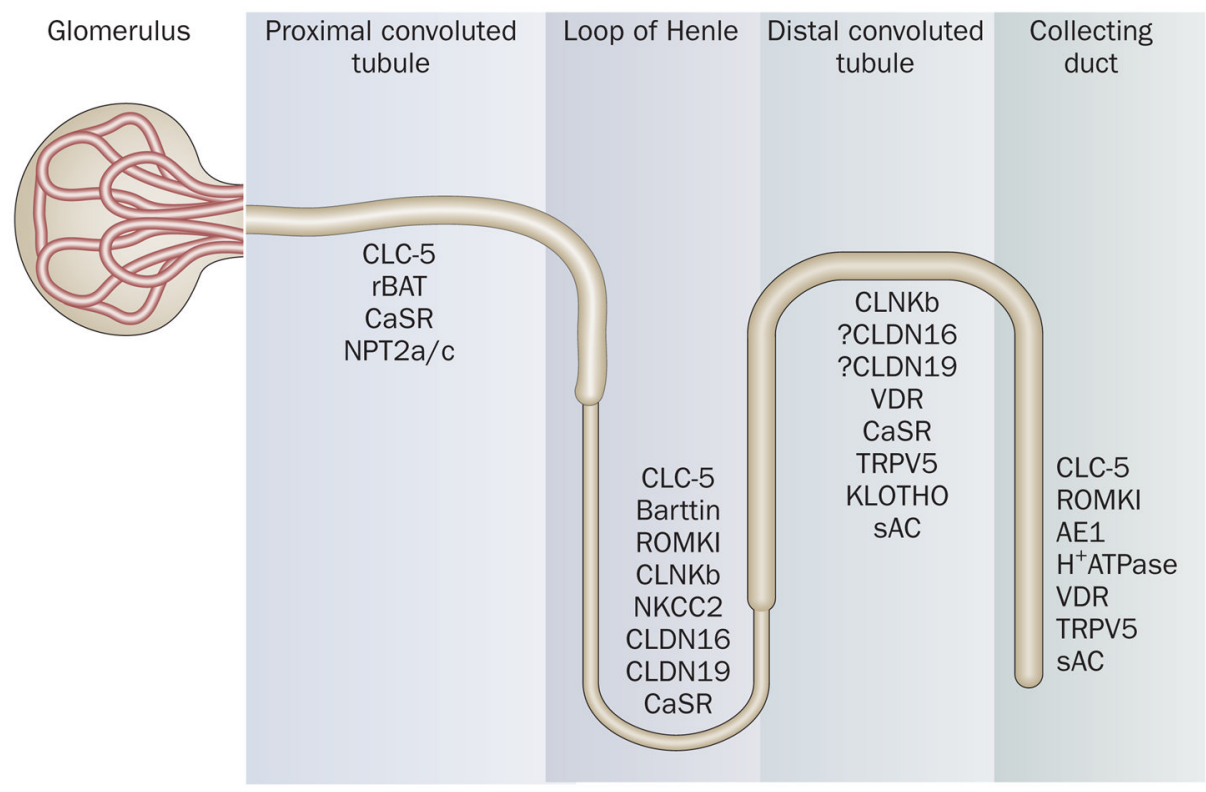

Figure 1.

Transporter, channel and receptor proteins of the renal tubule implicated in urolithiasis. 


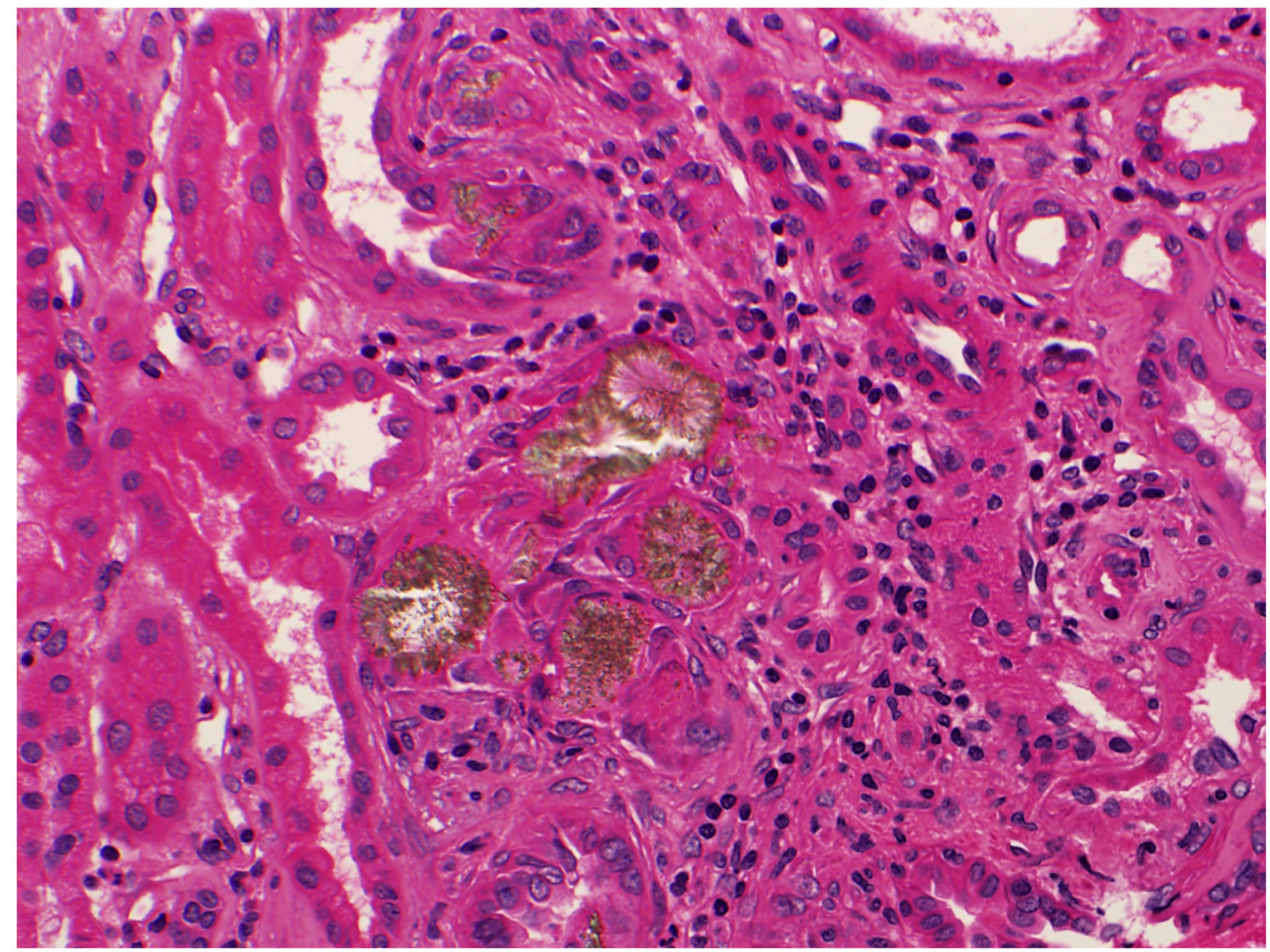

Figure 2.

Kidney biopsy tissue of a patient with APRT deficiency demonstrating reddish brown crystals of 2,8-dihydroxyadenine. 


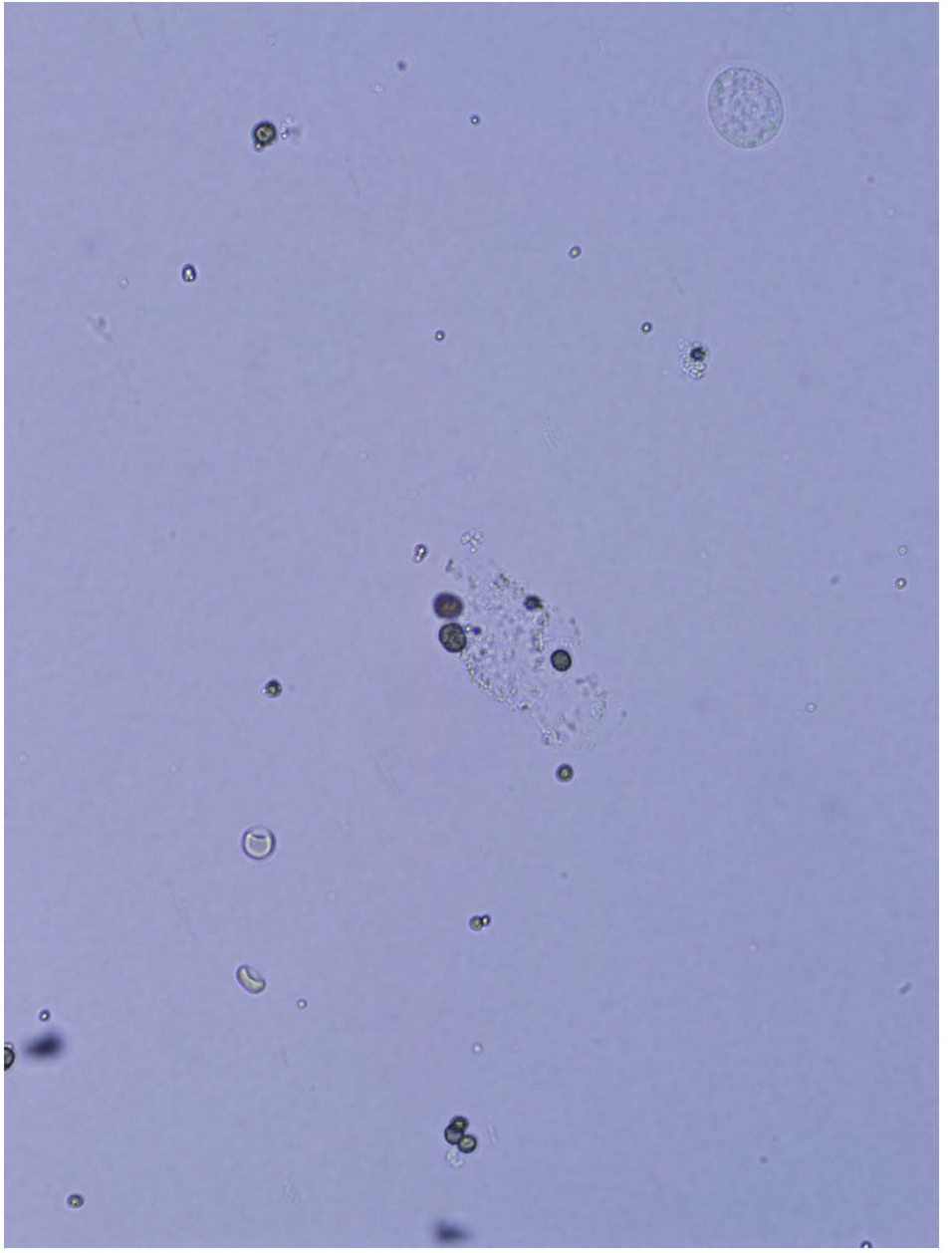

Figure 3.

Photomicrograph of 2,8-DHA crystals in the urine of a patient with APRT deficiency. 


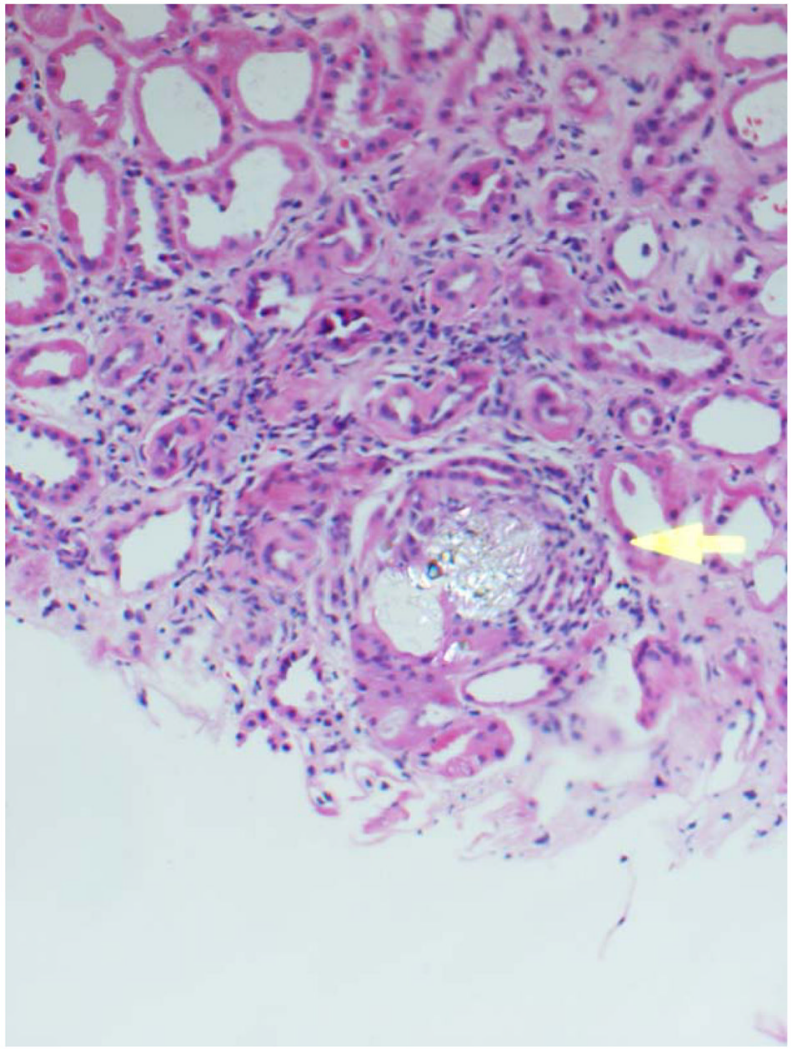

Figure 4.

Kidney biopsy tissue of a patient with primary hyperoxaluria demonstrating calcium oxalate crystals and associated inflammatory response (arrow).. 


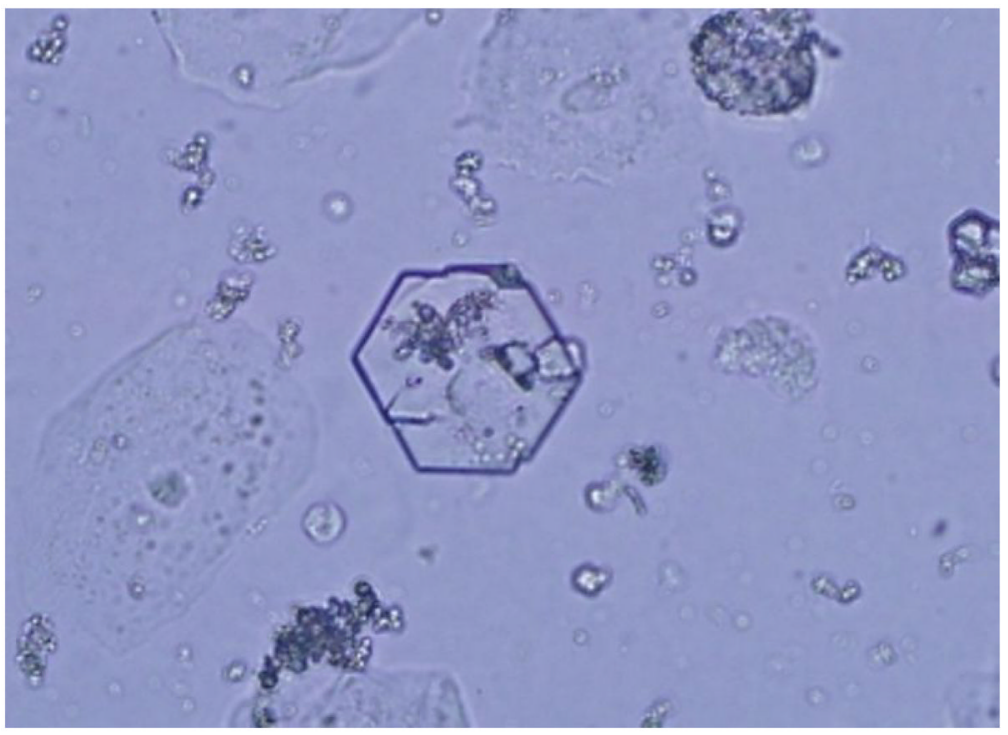

Figure 5.

Photomicrograph of cystine crystals in the urine. 


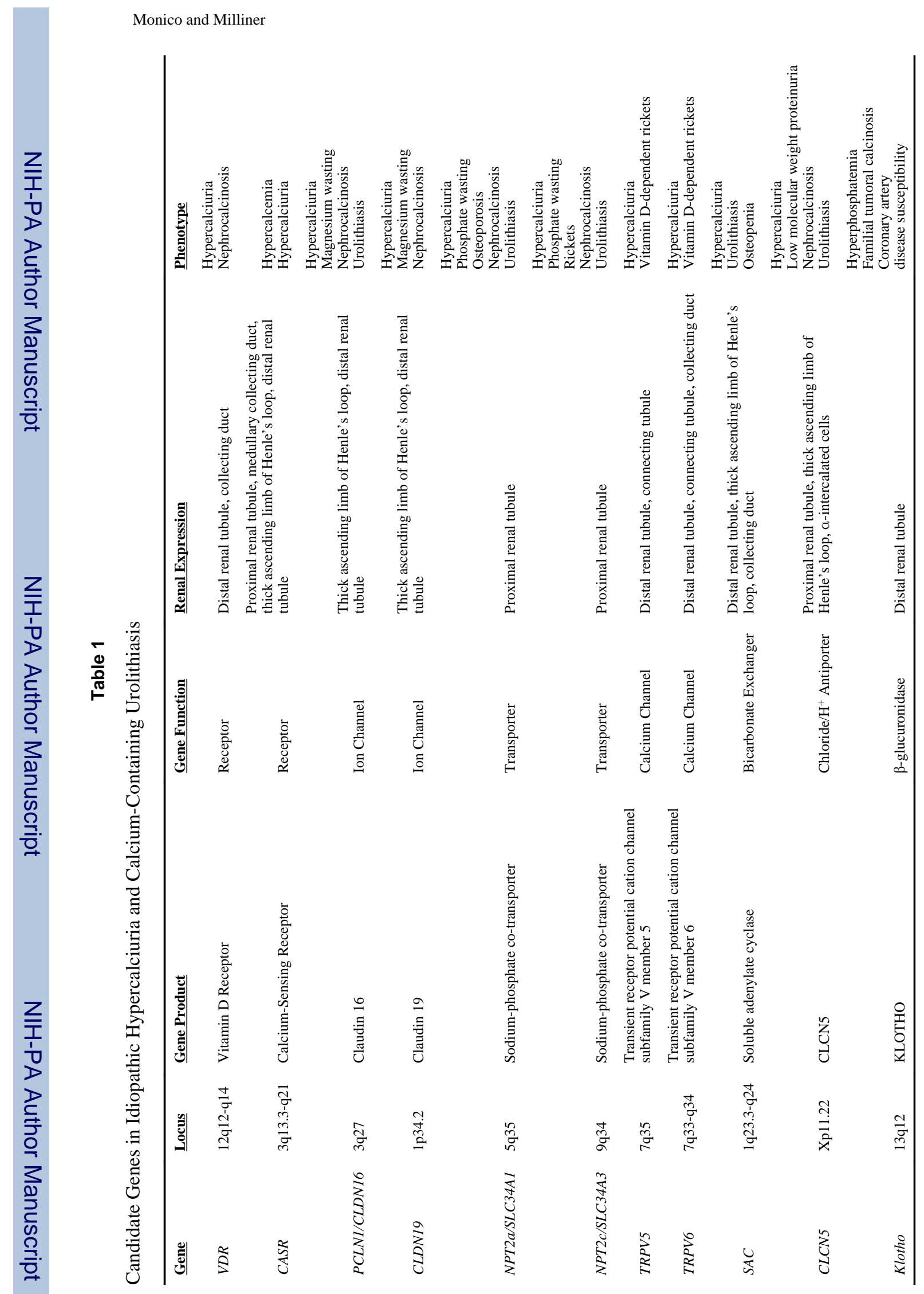

Page 21 


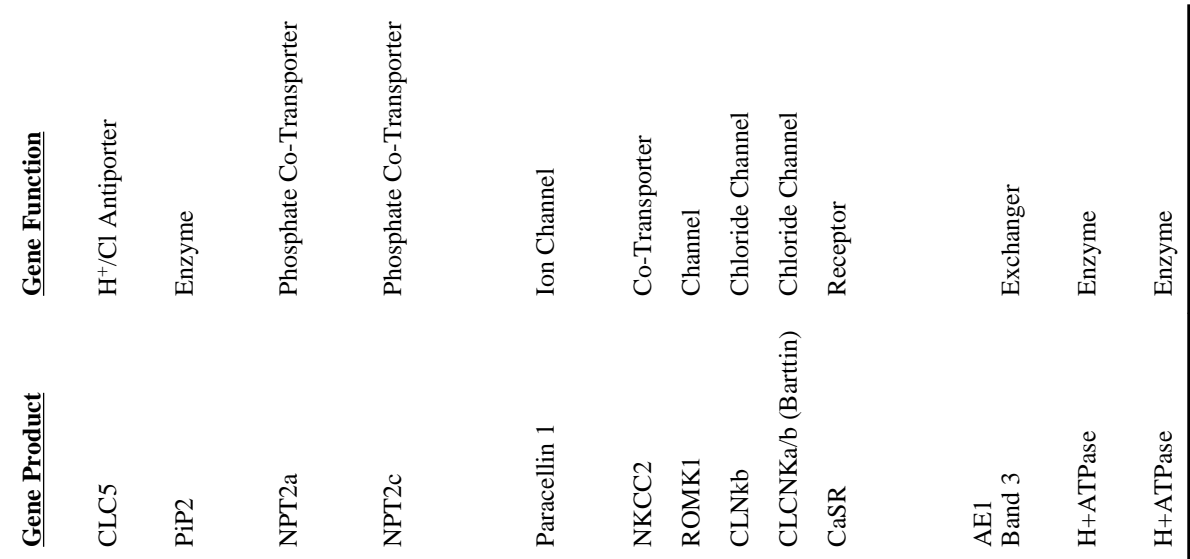

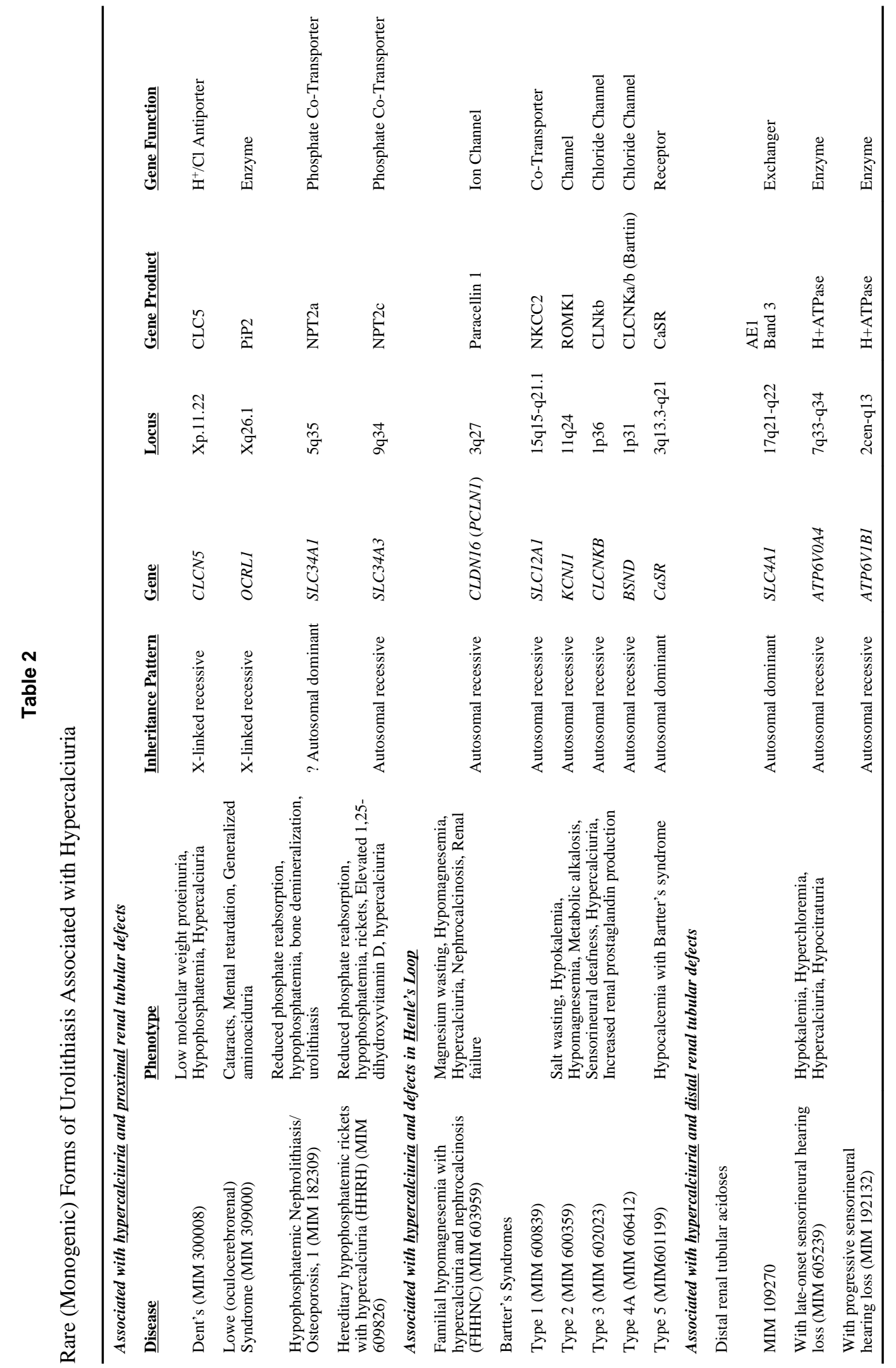




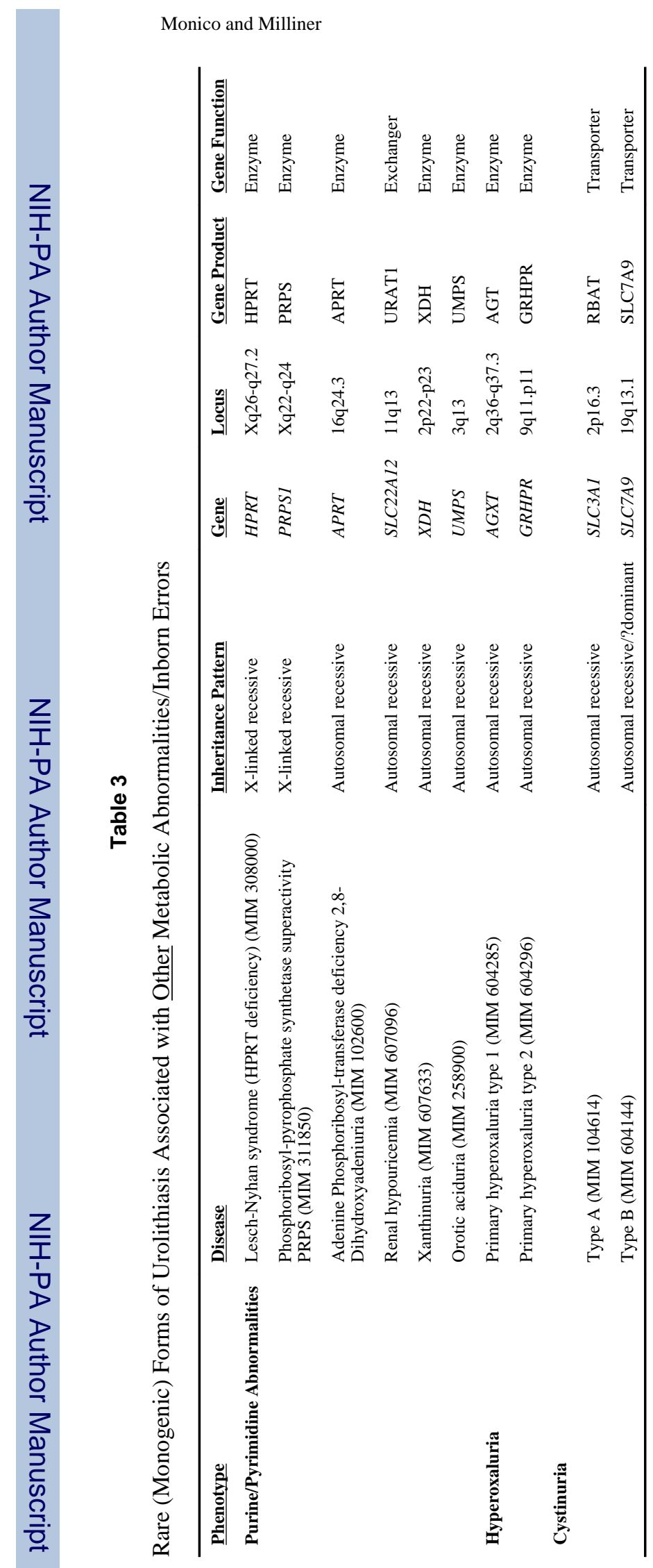

Page 23 